\title{
Research on Test Methods of Frame Torsional Rigidity
}

\author{
Lu JIA ${ }^{1,2}$, Huanyun DAI ${ }^{1}$ and Ye SONG $^{1}$ \\ ${ }^{1}$ State Key Laboratory of Traction Power, Southwest Jiaotong University, Chengdu 610031, China \\ ${ }^{2}$ E'mei Department of Mechanical Engineering, Southwest Jiaotong University, Emei 614200, China \\ a2008qianxun@163.com, bdaihuanyun@163.com, 'sy8621@163.com
}

Keywords: Frame, Torsional rigidity, Pipe beam, Box beam

\begin{abstract}
Frame torsional rigidity has great effect on the fatigue strength of the frame and the dynamic performance of vehicle. But the test for the frame torsional rigidity was very difficult. An improved torsional rigidity test method is proposed referring to analysis of distortion of frame in line running state and the definition of bogie torsional stiffness in the standard JIS E4207-2004. The improved test method is simple and practical, and error can be effectively controlled within $7 \%$. According to the different structure designed type, the frame is classified as box beam type frame and pipe beam type frame. Take advantage of improved torsional rigidity test methods respectively test the two type frames, meanwhile analyses the reason in theory why frame torsional rigidity of two types are different. The results show that: the size of the torsional rigidity mainly depends on the cross-sectional area of the side beam and the structure of cross beam. The torsional rigidity of the pipe beam type frame is smaller than the torsional rigidity of the box beam type frame.
\end{abstract}

\section{Introduction}

Frame is one of the most important load-bearing parts of a bogie. It is the installed basement for other bogie components, but also the carrier and force deliverer. During operation, affected by track irregularity, the bogie frame has been in a state of distorting support, the amount of deformation of the frame twisted depends on the frame stiffness. Frame stiffness mainly include vertical bending stiffness and torsional rigidity, frame rigidity directly affect the vehicle operation quality and safety.

So far, a lot of home and abroad rolling stock exporters have done plenty of experimental research on locomotives frame [1-4]. Research and test results show that the torsional rigidity of the frame mainly depends on the structure design pattern (beam type) [1, 4]. But there are great difficulties in the practical application process. This paper introduces test method of torsion rigidity in the standard JIS E 4207:2004 [5]. Analyze disadvantages of the method, at the same time, put forward an improved torsional rigidity test method. New torsional rigidity test method is used to analyze the frame, verify reasons of the torsional rigidity different. On the basis of study the torsional rigidity of frame structure fatigue strength and the influence of the bogie dynamic performance in order to provide some useful theoretical basis for development of high speed bogie in China.

\section{The definition of bogie torsional rigidity}

In the process of line running vehicles, under the influence of track distortion, the force on the first suspension parts of the bogie are uneven. Due to the increase or decrease in load condition, four suspension parts can't lead to bogie frame in a plane. Namely the frame is in a state of distortion. As shown in figure 1. 


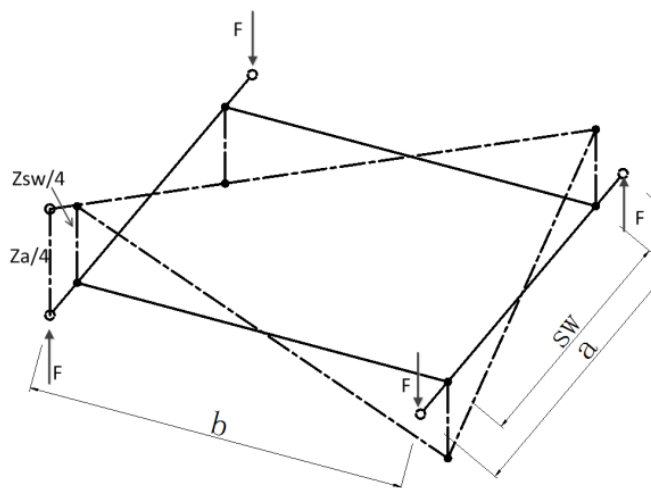

Fig. 1 the diagrame of the frame in the distorted state

In the figure, sw is the first suspension horizontal spacing of the frame. a the transverse distance between two wheels and rail contact points. $\mathrm{b}$ is bogie wheelbase. Zsw/4 is vertical displacement of the first suspension when the frame is in the distorted state. Za/4 is vertical displacement between two wheels and rail contact points.

The ratio of a series of changes in load of the first suspension and the amount of deformation of the first suspension is the torsional stiffness of the bogie frame. The calculation formula of the torsional rigidity is

$$
\mathrm{K}_{\mathrm{d}}=\frac{F}{z a / 4}
$$

Where, $K_{d}$ is the torsional stiffness of the bogie frame, $\mathrm{kN} / \mathrm{mm}$. $\mathrm{F}$ is load variation of a single wheel, $\mathrm{kN}$. $\mathrm{Za} / 4$ is vertical displacement between two wheels and rail contact points, mm. When the frame is in a state of distortion, the ratio of a series of relative deformation and wheelbase is defined as the frame distortion load. As shown in figure 2.

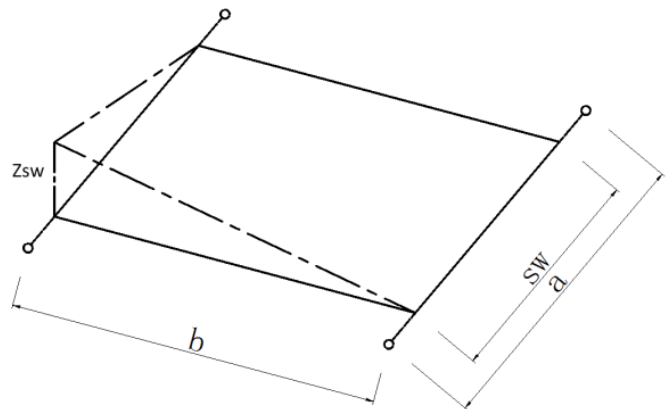

Fig.2 the definition of the frame distortion load

The distortion load $U$ of the bogie frame is defined as:

$$
\mathrm{U}=\frac{z_{\mathrm{sW}}}{\mathrm{b}}
$$

Where, $U$ is the distortion load of the frame. $\mathrm{b}$ is the frame wheelbase. Zsw is the first suspension relative elevation of the frame.

From geometric relationships of figure 1, it can be get that.

$$
\frac{z_{s w}}{z_{a}}=\frac{s w}{a}
$$

The formula (1) and (3) into Equation (2) to give:

$$
\mathrm{U}=\frac{z_{2} \times s w}{a \times b}=\frac{4 F \times s w}{k_{d} \times a \times b}
$$

The railway distortion load $U$ is defined in the railway standard: In general operating conditions, $\mathrm{U}$ is $5 \%$. In special supernormal conditions, $\mathrm{U}$ is $10 \%$

\section{Improved torsional stiffness test methods}

\subsection{Traditional torsional rigidity test method}

Referring to the definition of bogie torsional stiffness in the standard JIS E4207-2004《Railway Vehicle Bogie Frame-Design Principles》.In the first spring suspension, the frame is supported with rigid components. Imposing vertical loads on the angular position, the bogie produces vertical 
displacement. The axle base times the ratio of loads and displacement is torsional rigidity. Torsional rigidity testing method of the frame is shown in figure 3.

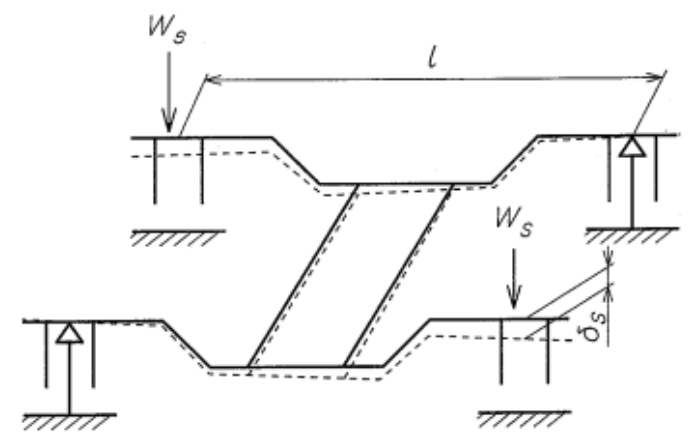

Figure 3: Torsional rigidity testing method of the bogie

The calculation formula of frame torsional rigidity is:

$$
K_{d}=\frac{W_{s} * I}{B_{s}}
$$

Where $\mathrm{K}_{\mathrm{d}}$ is the torsional rigidity of the frame, $\mathrm{MN} * \mathrm{~mm} / \mathrm{mm} ; \mathrm{W}_{\mathrm{s}}$ is the vertical load imposed on the two diagonal position in the first suspension, $\mathrm{MN} ; \mathrm{I}$ is the fixed axle base, $\mathrm{mm}$; $\delta_{\mathrm{s}}$ is the deformation in the first loaded place, $\mathrm{mm}$

\subsection{Improved torsional stiffness test methods}

Stiffness test methods in JIS E4207-2004, one of the frame corners is in the rigid bracing condition, while applying a load W_s to the oblique angle. Thereby, the latter generates displacement $\delta \_s$, the former generates no displacement.

This test methods is difficult in actual torsional rigidity test, there are usually two reasons: First, the load applied in the frame two angles at the same time is more dangerous, also cannot guarantee the synchronization and equally of the load, leading to large deviations test results; Second, the frame first suspension system consist of rubber pads and steel springs, which is under the elastic support conditions, rather than under the rigid support conditions, cannot be tested in accordance with the standards method. It is more trouble if change the elastic suspension for the rigid support. Based on this, this paper presents an improved test method shown in Figure 4.

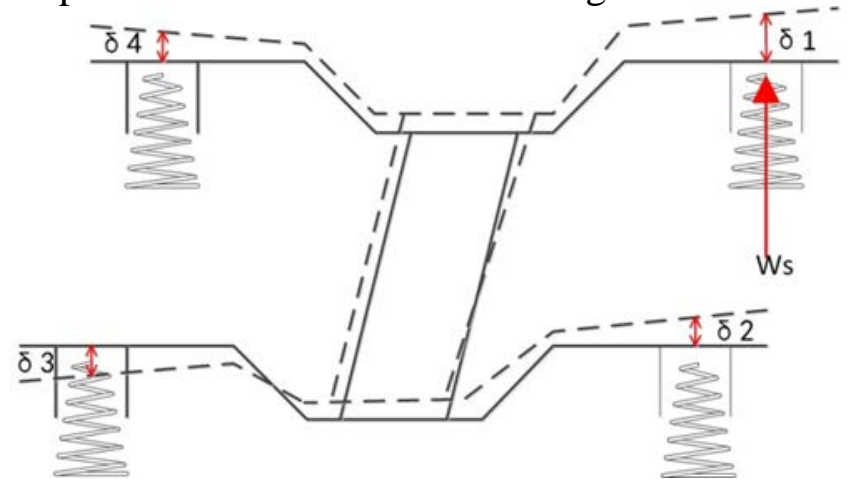

Fig. 4 Improved torsional stiffness test methods

According to the test methods, the calculation of torsional rigidity formula is:

$$
K_{d}=\frac{W_{s} * 1}{\delta_{1}-\delta_{2}+\delta_{\mathrm{s}}-\delta_{4}}
$$

Where $K_{d}$ is the torsional rigidity of the frame, $\mathrm{MN} * \mathrm{~mm} / \mathrm{mm} ; W_{s}$ is the vertical load imposed in the first suspension, $\mathrm{MN}$; $\mathrm{I}$ is the fixed axle base, $\mathrm{mm}$;

$\delta_{1} 、 \delta_{2}, \delta_{3}, \delta_{4}$ are the displacement in the four first suspension location, mm.

Using three method test the torsional stiffness for a frame, the three methods are: First, the first suspension in the rigid supporting conditions, the load $W_{s}$ is applied in kitty corner, which is according to JIS E4207-1992 measurement. Second, the first suspension in the elastic support conditions, the load $W_{s}$ is applied in kitty corner, measure four deformation in the first suspension; Third, the first suspension in the elastic support condition, the load $W_{s}$ is only applied in one corner, measure four deformation in the first suspension. The measurement results in Table 1 below: 
Table 1: Three kinds of programs frame torsional stiffness test results

\begin{tabular}{lll}
\hline program & $\begin{array}{l}\text { torsional stiffness } \\
\text { MN*mm/mm }\end{array}$ & $\begin{array}{l}\text { error } \\
\%\end{array}$ \\
\hline Program 1 & 12.736 & ----- \\
Program 2 & 11.972 & 6.38 \\
Program 3 & 12.960 & 1.75 \\
\hline
\end{tabular}

The frame torsional stiffness value of test program 1 is defined as a standard value. The value of program 2 is lower, while the test value of program 3 is more correct. Two improves test programs are controlled within $7 \%$ error. It can be seen that. New torsional rigidity test method can effectively solve problem which is difficult in the practical engineering of frame torsional rigidity test.

Due to the program 2 and 3 is processed in the state of elastic support; the amount of deformation of the frame itself is far less than the amount of deformation of the elastic support. So in the process of test, it should use more precise displacement measurement equipment, and the test should be repeated several times to observe whether there is a discrete data.

\section{Effect on the torsional rigidity of frame structure}

Currently under the high speed emu welding structure is commonly concave type ' $\mathrm{H}$ ' [6]. The main structure is tailor-welded by the side beams and cross beams, where various positioning fitting seats are welded. Frame side beams are basically the same, which are all welded into the fish belly box structure by the upper and lower cover plate and the vertical plate, while internal structure are welded with reinforcement plate. First suspension spring seats are composed of cylindrical steel plate overall welding, cast steel turning arm positioning seats are welded in the side beams arc transition. Anti-yaw damper seats are welded outside the side beam vertical plates. The difference is mainly beam section, in two forms of pipe transom and box transom. Usually motor soleplate, gear box boom soleplate and brake soleplate and so on are welded on the beam. So the bogie according to the structure types are divided into pipe transom and box transom. See figure 5 and figure 6.

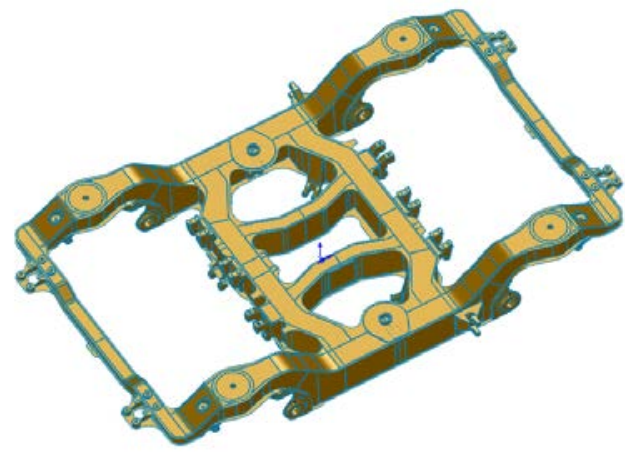

Figure 5: Box beam bogie

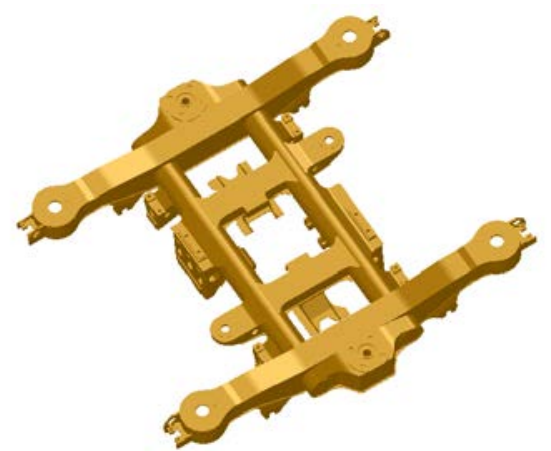

Figure 6: Pipe beam bogie

\subsection{Frame side beam structure}

Generally frame side beams are welded into box structure by upper and lower cover plate and web plate. The bending stiffness [7-8] is:

$$
K_{\mathrm{bs}}=\mathrm{E} * I_{\mathrm{bs}}
$$

Where $K_{\mathrm{bs}}$ is bending stiffness of side beams, $\mathrm{N} / \mathrm{mm}^{2}$; E is material elastic modulus, MPa; $I_{\mathrm{bs}}$ is moment of inertia of the side beam section, $\mathrm{mm}^{4}$.

The torsional rigidity is:

$$
K_{\mathrm{d} s}=\frac{4 G \approx A}{\oint_{\mathrm{h}(s)}}
$$


Where $K_{\mathrm{d} s}$ is torsional rigidity of side beam, $\mathrm{MN}^{*} \mathrm{~mm} / \mathrm{mm}$; $\mathrm{G}$ is material shearing elastic modulus, MPa; A is side beam section area, $\mathrm{mm}^{2} ; \oint \frac{\mathrm{d} s}{h(\mathrm{~s})}$ means integrating the week along the centerline of cross-section.

According to the structure characteristics of the bogie frame, the side beams structures are basically same. A variety of materials frame using are basically the same. Therefore, it can be seen from formula (8), the main factor affecting side torsional stiffness is the cross-sectional area of side beams. When a large cross-sectional area of the side beams, the torsional stiffness is large, whereas the smaller torsional rigidity.

\subsection{Frame transom structure}

EMU frame transom has two structural forms, one is welded into a closed box section structure by the upper and lower cover plate and the vertical plate. It is called as box beam type frame for short. One is welded into a closed section pipe structure by hollow cylindrical materials, which is called as pipe beam type frame for short.

\subsubsection{Box-type beam frame structure}

Transom section of the box beam type frame is box-type structure, also can be divided into open form and closed form, as shown in Figure 7.
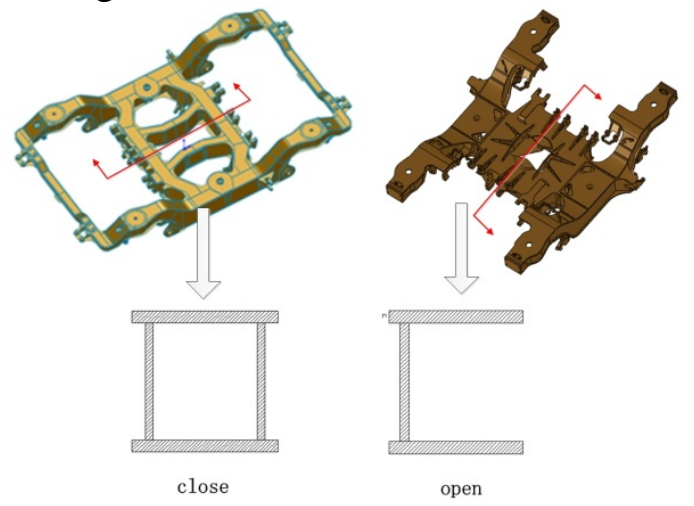

Figure 7: Forms of box beam type frame transom section

The bending stiffness is:

$$
K_{\mathrm{bt}}=\mathrm{E} * I_{\mathrm{bt}}
$$

Where $K_{\mathrm{bs}}$ is bending stiffness of transoms, N/mm²; $I_{\mathrm{bt}}$ is moment of inertia of the transoms section, $\mathrm{mm}^{4}$.

The torsional rigidity is:

$$
K_{\mathrm{dt}}=\frac{4 G * \mathrm{~A}}{\oint_{\mathrm{h} t \mathrm{ds} ?}}
$$

Where $K_{\mathrm{ds}}$ is torsional rigidity of transoms, $\mathrm{MN} * \mathrm{~mm} / \mathrm{mm}$.

It can be seen from formula (10), the section open or closed of the box beam frame transoms have a greater impact on torsional stiffness. Torsional stiffness of the open box beam frame is less than the closed box beam frame.

\subsubsection{Pipe beam type frame structure}

Transom section of the pipe beam type frame is circle structure, as shown in Figure 8.
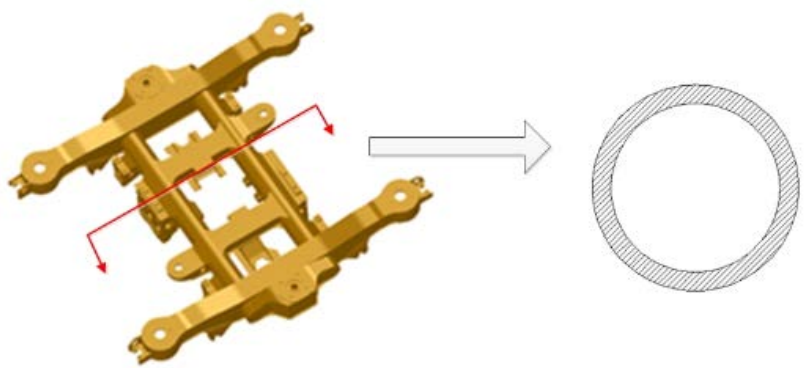

The bending stiffness is:

Figure 8: Forms of pipe beam type frame transom section

$K_{\mathrm{bt}-\mathrm{b}}=\frac{\pi \mathrm{E}}{64}\left(D^{4}-d^{4}\right)$ 
Where $K_{\mathrm{bs}}$ is the bending stiffness of transoms, N/mm²; D is the diameter of the outer the circle of transoms section; $d$ is the diameter of inner circle of transoms section.

The torsional rigidity is:

$K_{\mathrm{dt}-\mathrm{b}}=\frac{\pi \mathrm{E}}{32}\left(D^{4}-d^{4}\right)$

Where $K_{\mathrm{ds}}$ is torsional rigidity of transoms, $\mathrm{MN}^{*} \mathrm{~mm} / \mathrm{mm}$.

From formula (10) and (12) we can see, different types of frame structure have different torsional rigidity. The frame torsional rigidity has close relationship with the wall thickness of construction material. Table 2 lists the frame torsion stiffness and first-order bending frequency of pipe beam frame and box beam frame.

Table 2: Comparative table of different frame type torsional rigidity

\begin{tabular}{|c|c|c|c|}
\hline Frame type & & $\begin{array}{l}\text { torsional rigidity } \\
\mathrm{MN}^{*} \mathrm{~mm} / \mathrm{mm}\end{array}$ & $\begin{array}{l}\text { Frequency of torsional } \\
\text { vibration mode }(\mathrm{Hz})\end{array}$ \\
\hline \multirow[t]{2}{*}{ Box beam frame } & d close & 13.951 & 41.25 \\
\hline & open & 12.736 & 40.14 \\
\hline Pipe beam frame & & 11.015 & 39.09 \\
\hline
\end{tabular}

As shown in Table 2. Torsional stiffness of box beam frame is larger than the pipe beam frame. Torsional stiffness of the open box beam is less than the closed box beam.

\section{Conclusions and Prospect}

To sum up, may draw the following conclusions:

Through the improved method of torsional rigidity test, Frame can be under the condition of the elastic support by applying load approximate single angle measuring torsional rigidity; measurement error has been effectively controlled. Through simulation and test analysis, the measurement results of the improved distortion stiffness test method with the theoretical value deviation less than $7 \%$.

In the process of rigid test under elastic support condition, the test should be repeated several times to observe whether there is a discrete data because of the influence of elastic support.

The frame torsional rigidity mainly depends on the size of the measurement of cross-sectional area and the structure of beams. Torsional stiffness of box beam frame is larger than the pipe beam frame. Torsional stiffness of the open box beam is less than the closed box beam.

\section{Acknowledgement}

This research was financially supported National "863" plan project High-speed train spectrum module construction and key technology of integration design (2012AA112001-02). '12.5' national sci-tech support plan project the higher level of speed emu bogie key technology research and equipment development (2011BAG10B01-A01). Natural fund: High-speed train wheel/rail profile matching with sinusoidal movement mechanism research (51475388)

\section{References}

[1] AN Qi , LI Fu . "Influence of structure mode on distortion stiffness of bogie frame”. Journal of Traffic and Transportation Engineering, 2008, 8(6): 1-5, 121.

[2] RUBEL M. "Influence of types of structural stiffness of the bogie frame on the resiliency properties of the bogie". Proceedings of the 6th International Conference on Railway Bogies and Running Gears . Budapest: BUTE, 2004: 2772286.

[3] ORLOVA A, BORONEN KO Y, SCHEFFE L H, et al. "Tuning von güterwagendrehgestellen durch radsatzkopplungen”. ZEV Rail Glasers Annalen , 2002 , 126 ( 9) : 2002212 
[4] Han Jingang, Fu Maohai, An Qi, Deng Xiaoxin. "Research on Distortion Stiffness in 日-type Welded Frame of Freight Wagon”. RAILWAY LOCOMOTIVE \& CAR Vol.29 No.5 Oct. 2009.

[5] Japanese Industrial Standards. “JIS E 4207 Truck Frames for Rail way Rolling Stock - General Rules for Design”. Tokyo, Japanese Industrial Standards, 2004.

[6] Yan Bingao, Fu Maohai. "Vehicle Engineering”. Beijing, China Railway Publishing House, 2008.

[7] Ling Qinghua. "Mechanics of Materials”. Chengdu, Southwest Jiaotong University Press, 2002.

[8] Xu Zhilun. “Elasticity”. Higher Education Press:2006 